\title{
The nutrition and health transition in Thailand
}

\author{
Vongsvat Kosulwat*
}

Institute of Nutrition, Mahidol University, Phutthamonthon, Salaya, Nakhon Pathom, Thailand 73170

\begin{abstract}
Objective: To explore and describe the nutrition and health transition in Thailand in relation to social and economic changes, shifts in food consumption patterns and nutritional problems, as well as morbidity and mortality trends.

Design: This report reviews the nutrition and health situation and other related issues by compiling information from various reports and publications from several sources. Yearly statistics and reports from the National Statistical Office were used as well as data from the Food and Agriculture Organization (FAO) and national surveys on the nutrition and health situation of the Thai population.

Results: Thailand has undergone social and economic transitions during the past three decades and is approaching the post-demographic transitional period. These are evidenced by an increase in life expectancy at birth of the population, and declines in the total fertility and infant mortality rates. The economic structure has also moved from agricultural to industrial. Industrial growth has surpassed that of the agricultural sector as indicated by a steady rise in the share of the industrial sector in the gross domestic product, which is greater than that of other sectors. At the same time, results from several nation-wide surveys indicate that the food consumption pattern of the population has changed considerably; Thai staples and side dishes are being replaced by diets containing a higher proportion of fats and animal meat. A shift in the proportion of expenditure on food prepared at home and that expended on purchased, ready-to-eat food, in both rural and urban settings, gives another reflection of the change in food consumption of the Thai population. The prevalence of overweight and obesity among children and adolescents has increased dramatically during the past 20 years and is more pronounced in children from private schools and urban communities than in those from public schools or rural areas. Among adults, results from two national surveys in 1991 and 1996 indicated that the problem of overweight and other risk factors for cardiovascular disease have increased significantly. In considering the overall causes of death among the Thai population, the leading causes are diet-related chronic degenerative diseases. Diseases of the circulatory system have become the number one cause of death in Thailand and cancer has ranked as the number three cause of death since the late 1980s.

Conclusions: The rapid changes in food intake and lifestyle patterns in Thailand clearly demonstrate a significant impact on the shifting pattern of disease burden of the population. These changes should be monitored carefully and must be reversed through appropriate behaviour modification and the promotion of appropriate eating practices and physical activities.
\end{abstract}

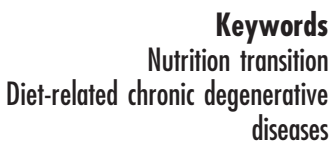

Rapid socio-economic development accompanied by increased urbanisation and Westernisation have transformed the lifestyles and dietary practices of populations within the Asia and Pacific region ${ }^{1,2}$ over the past decade. Experiences from China, Japan and Korea show higher trends in the incidence of chronic degenerative diseases such as obesity, hypertension, diabetes mellitus, heart diseases, stroke, certain cancers and osteoporosis ${ }^{3-9}$. These are largely the result of drastic changes in personal and family lifestyles regarding food intake patterns. Eating patterns have shifted from a traditional Asian diet - cerealbased and low-fat - to a more Westernised diet characterised by increased consumption of animal products, fats and sugars and decreasing consumption of complex carbohydrate foods. Population ageing, sedentary lifestyles, the trend towards smaller families and increased urbanisation are other important factors contributing to the increased prevalence of chronic, dietrelated diseases.

Thailand has been faced with the phenomena of economic and health transitions ${ }^{10}$ since the mid 1980s. The economic structure has shifted from agriculture to industry and commerce, resulting in inequitable income distribution. Social structure and lifestyle have changed from a rural orientation to an urbanised society, resulting in increased migration; family structure has changed from 
extended to nuclear families; and the age structure has changed from a predominantly young population to a greater number of adults and elderly. Changes were also observed in the food system of Thai society: food was produced for sale and exportation rather than for domestic consumption; food for consumption was purchased rather than produced; rural food distribution problems developed; marketing did not keep pace with rapid rural changes; and food consumption was influenced by commercials and advertising. To view this nutrition and health transition in relation to all other social changes, the changing patterns of demography, disease and food consumption will be discussed in this paper.

\section{Social and economic changes in Thailand}

\section{Demographic transition}

Thailand, a country of 513000 square kilometres, is situated on the Indochina peninsula of Southeast Asia. The population was estimated to be 61 million in 1999 with approximately three-quarters of the population residing in rural areas. At present, Thailand is approaching the postdemographic transitional period and has made considerable progress in health development ${ }^{11}$. Extensive family planning programmes during the past two decades have reduced the population annual growth rate from $3.2 \%$ in 1970 to an estimated $1.2 \%$ in 2000. Life expectancy increased from 58.6 to 67.4 years for males and from 63.8 to 71.7 years for females during the period $1974-2000$, and should reach 69.5 years for males and 73.6 years for females by 2015. Furthermore, the life expectancy for 60-year-olds has also risen from 15.3 to 20.3 for males and 17.4 to 23.9 for females ${ }^{11}$. The nation's total fertility rate has dropped to 3.0 births per woman in 1990 from 5.2 in 1975, while a crude death rate declined to 5.2 per 1000 in 1998 from 13.5 per 1000 in 1960. Together with the significant decline in the infant mortality rate $(4.5$ per 1000 live births in 1998 vs. 27.9 per 1000 live births in 1964), these demographic transitions have changed the age structure of Thailand's population from that of a broad base, pyramid-like shape in 1970 to a columnar base, pagoda-like form at present. Based on these past changes and anticipated future trends, Thailand is expected to have more people in the active age group (ages 14-60 years) in the next decade and the pattern of dependency ratio will shift towards a higher proportion of people over 60 years of age than children under 14 years of age.

\section{Changes in economy of the nation and bousebold}

Economic growth can be a major determining factor of the social change of a nation; during the past 30 years Thailand has transformed rapidly from a subsistence agrarian society into an industrial society, especially during the 1980s. The share of the industrial sector in the gross domestic product (GDP) rose from the 1960 level of $12.52 \%$ to $15.95 \%$ in 1970 , increased steadily to $31.4 \%$ in
1996, and was expected to be steady during the Asian economic crisis. At the same time, the GDP from the agricultural sector fell from $39.79 \%$ in 1960 to $25.9 \%$ in 1970 and continued to decline to $10.7 \%$ in $1996^{11}$. A shift in economic structure not only indicates social changes of the Thai population, it indirectly indicates a shift in the physical activity pattern from labour-intensive to more sedentary; which may contribute to the rising incidence of diet-related chronic degenerative diseases.

Gross national product (GNP) per capita is regarded as the most visible index of the economic level of a nation; Thailand is a nation in which the GNP has changed dramatically. Thailand has experienced steady economic growth with an average annual economic growth rate of 7\%, except since the Asian economic crisis of mid 1997. Per capita GNP increased from US\$ 80 in 1960 to US\$ 162 in 1970 , to US\$ 563 in 1980, to US\$ 1543 in 1990, and finally to more than US\$ 3000 in 1996. However, the negative impact of the economic growth crisis is clearly evident by a fall of the per capita GNP to US\$ 1847 in 1998. This resulted in a decline in the annual economic growth rate to $-9 \%$ but was expected to improve to $3.5 \%$ in the year 2000 .

The increase in economic growth and the reduction in population growth rate before the economic crisis reduced the proportion of the population living below the poverty line from $57.0 \%$ in 1962 to $11.4 \%$ in 1996; but this increased slightly to $13.0 \%$ in $1997^{11}$.

\section{Food consumption and dietary patterns}

\section{Traditional Thai eating pattern}

A new diet-health paradigm may be evolving that places more emphasis on the positive aspects of diet. The paradigm goes beyond the role of food constituents as essential nutrients required for sustaining life and growth, to one of preventing or delaying the onset of chronic diseases later in life. The food patterns, reported to confer longevity by promoting good health and prevent the premature onset of chronic disease later in life, are diets rich in cereals, legumes, vegetables and fruits, low in animal foods, and moderate in low-fat meats such as fish ${ }^{1}$. These are consistent with the traditional Thai eating pattern. The origin of the Thai diet begins with the waterborne community. From information in King Ramkhamhaeng's famous stone inscription in the early 13th century, it is clear that rice and fish were the major ingredients of Thai cuisine. Aquatic animals, plants and herbs are still used a great deal in preparing meals; large pieces of meat are rarely used in any dish. The common cooking methods still widely practised are stewing, grilling and baking; frying is an influence of Chinese cuisine. Fresh spices and herbs are common, basic ingredients in most Thai dishes. In a proper Thai meal, dishes are not served in courses; instead, they are served at the same time allowing the various dishes to complement and enhance each other. All 
dishes are eaten with rice, which is a main staple for the Thai population.

\section{Pattern of food expenditure}

The linkages between food production and the nutritional status of the individual consumer are very complicated. Ample food production does not always guarantee adequate consumption. Household food acquisition and individual consumption are influenced by food prices, family income, food habits and cultural food beliefs, nutritional knowledge and advertisements, tastes and preferences. The transition of food consumption patterns of a population is a consequence of economic development. Currently, Thai staples and side dishes are being replaced by diets containing higher proportions of fats and animal meat, and less vegetables and fruits. This phenomenon is common in the big cities of Thailand, especially among inhabitants with higher incomes and the younger generation. Concomitant with these trends is the selection of food that requires less time and skill to prepare. Home-made meals are rarely seen and are being replaced by ready-to-cook and ready-to-eat foods bought at local markets, food stalls, supermarkets or big department stores and eaten at home.

The National Household Economic Surveys conducted between 1990 and 1999 collected information on household income, expenditures and housing characteristics. The data on average food expenditure on each food group item collected by this survey provide a rough prediction of the dietary pattern of the family ${ }^{12-16}$. The dietary pattern and the total expenditure on food in the family can be important indicators of food security at national and household levels. The less spent on food - compared with the total expenditures of a family - the better the food security welfare of the family. About 33\% of total expenditure, on average, was spent in Thailand on food and beverages in 1999; one of the lowest percentages in Asia, indicating widespread household food security. The food expenditure in 1990 was approximately 29.8\% for the greater Bangkok area and 33.0\% for the urban area, which decreased to $28.5 \%$ and $28.8 \%$ by 1999 , respectively. Food expenditure in the rural areas in 1990 was roughly $40.4 \%$ and decreased to $37.0 \%$ in 1999.

Another interesting finding from these biannual National Household Economic Surveys since 1990 verified the shift in the proportion of expenditure on food prepared at home and that expended on purchased, ready-to-eat food. Nearly $50 \%$ of the expenditure on food in greater Bangkok was for purchased, ready-to-eat food, while less than 30\% of income was spent in all four national regions (Northern, Northeast, Central and Southern). People in rural areas spent only $12.2 \%$ of food expenditure purchasing ready-to-eat food in 1990 , which increased to $21.7 \%$ in 1999 . All areas now tend to spend more money on food from outside as compared with 1990.
The expenditures for some food items showed a positive trend from 1990 to 1999. The expenditure on sugar and sweeteners increased from 1.8\% in 1990 to 3.0\% in 1999. People in the Central region increased their consumption of sugar and sweeteners more than other regions. The increased expenditure on fats and oils was minimal, only $0.3 \%$.

\section{Dietary intake pattern}

Typical, or traditional, dietary patterns rely heavily on rice as the main source of calories and protein. However, dietary changes were noticed with social changes. This is the same type of nutrition transition undergone by almost every country in the East. The dietary pattern changes can be explained in two ways - changes in major food consumption and nutrient intakes. During 1960-1995, the per capita consumption of tubers and cereals, especially rice, declined by about one-third of the level consumed in the early 1960s (Table 1 ). Consumption of animal products started to increase after 1975 and a drastic change occurred in 1986. Animal product consumption increased because more food was available, the distribution of food within the family was better, and nutritional knowledge about the causes of malnutrition was better. These speculations may also explain a trend towards increased consumption of fruits and vegetables from 1960 to 1986. There was an increased consumption of fats and oils from 1960 to 1986 but a decline was observed in 1995. This phenomenon can be partly explained by public consciousness about the preventive measures for hypercholesterolaemia and heart disease. Nevertheless, a steady increase in sugar consumption was observed during the three decades. One of the positive behavioural changes was the increased intake of vegetables and fruits over this period of time and it has remained steady since $1986^{17-19}$.

The latest estimated nutrient caloric intake for Thailand, from food balance sheets, was $2290 \mathrm{kcal}_{\text {person }}{ }^{-1} \mathrm{day}^{-1}$ and protein intake was $49 \mathrm{~g}_{\text {person }}{ }^{-1} \mathrm{day}^{-1}$. Trends over the last two decades show that caloric availability has been stable $^{20}$ at $2200-2300 \mathrm{kcal}_{\text {person }}{ }^{-1} \mathrm{day}^{-1}$. However,

Table 1 Changes of food consumption in Thailand, 1960-1995

\begin{tabular}{lrrrr}
\hline & \multicolumn{4}{c}{ Year of survey } \\
\cline { 2 - 5 } Food item & 1960 & 1975 & 1986 & 1995 \\
\hline Rice, cereals and tubers $(\mathrm{g})$ & 440.2 & 374.0 & 350.9 & 305.7 \\
Meat and poultry (g) & 17.5 & 27.0 & 80.0 & 71.4 \\
Fish and shellfish (g) & 46.3 & 51.0 & 54.4 & 46.1 \\
Eggs (g) & 4.2 & 14.0 & 23.9 & 21.4 \\
Milk and products (g) & - & - & 70.9 & 29.3 \\
Pulses and products (g) & - & 4.0 & 56.9 & 9.1 \\
Vegetables (g) & 81.9 & 106.0 & 115.9 & 113.4 \\
Fruits (g) & 6.1 & 36.0 & 99.2 & 73.6 \\
Fats and oils from animal source $(\mathrm{g})$ & 0.8 & 6.0 & 13.5 & 1.9 \\
Fats and oils from plant source $(\mathrm{g})$ & 19.0 & 22.0 & 9.6 & 12.1 \\
Sugar $(\mathrm{g})$ & 0.2 & 7.0 & 13.6 & 13.7 \\
\hline
\end{tabular}

Source: Nutrition Division, Department of Health, Ministry of Public Health ${ }^{8,19}$. 
actual food consumption (in contrast to food balance sheets) data, derived from the 1995 National Nutrition Survey by the Division of Nutrition, Ministry of Public Health, revealed that the average daily caloric intake of the Thai population (except those in greater Bangkok) was $1751 \mathrm{kcal}_{\text {person }}^{-1}$, a decrease from $1821 \mathrm{kcal}_{\text {person }}{ }^{-1}$ in 1960 (Table 2). The data also indicated that the protein proportion of the total calories consumed increased slightly to $13.2 \%$ (equivalent to $58.1 \mathrm{~g}$ of protein per person) from $10.8 \%$ in 1960; the proportion of animal protein to total protein was 51.1\% compared with $31 \%$ in 1960. The percentage of energy intake from fat increased to $22.2 \%$ of total calories from $8.9 \%$ in 1960 , implying a trend towards diversity in the diet. The caloric distribution shows that nearly $60 \%$ of total calories come from carbohydrates, and fat consumption is low. However, results from a survey in a selected population in greater Bangkok showed that only half of the total calories came from carbohydrates and more than 30\% came from fat ${ }^{21}$. The average intake of micronutrients was generally adequate per recommended daily dietary allowances (RDA), except for calcium and that remains insufficient only $40.7 \%$ of the RDA standard ${ }^{17-19}$.

\section{Nutrition situation and trends}

Despite the overall thriving economic conditions and the bounty of food during the 1980s and 1990s, there are still considerable nutritional problems. However, during the 1980s, Thailand achieved a dramatic reduction in the magnitude and severity of malnutrition in pre-school children and virtually eradicated the severe form of malnutrition $^{22}$, to $0.0035 \%$ in 1991 from $2.13 \%$ in 1982 . Nutritional surveillance reports from the Nutrition Division of the Ministry of Public Health indicate that Thailand has achieved dramatic reductions in the proportion of underweight children. The percentage of underweight children $(<5$ years old) was estimated at $22 \%$ in 1987 , significantly lower than an estimated $36 \%$ in 1982 . The estimated prevalence of underweight in 1990 was about 13\%, amongst the lowest in Asia ${ }^{10}$. Nevertheless, due to uneven prosperity distribution, inadequate consumer protection and unmitigated environmental degradation, Thailand is enduring a new nutrition-related health threat of malnutrition and other deficiency diseases coexisting with the diseases of affluence. Current emerging nutritional problems, especially the diseases of affluence, and their trends are summarised in the discussions that follow.

\section{Shift in trend of obesity}

Obesity is emerging as a global problem, affecting both developed and developing countries. At present, the prevalence of obesity occurs most frequently in developing countries including Thailand. Obesity has been largely ignored in health and nutrition strategies developed at national and international levels in contrast to other chronic non-communicable diseases. Only recently has the global obesity problem been recognised as a major public health issue that demands urgent attention?

\section{Childhood and adolescent obesity}

The pattern and trends of overweight and obesity of the Thai population have received more attention during the past two decades than ever before. The prevalence of overweight and obesity among children and adolescents has increased dramatically during the past 20 years. Results from periodic cross-sectional surveys in primary school children in greater Bangkok from 1992 to 1994 demonstrated that, among 2885 school children (6-12 years old), the prevalence of overweight and obesity among middleto high-income families was between $25.7 \%$ and $27.4 \%$, while in those from middle- to low-income families, it was $11.2 \%$. After three years of follow-up, the prevalence of overweight and obesity increased to $28.1-32.3 \%$ and $14.6 \%$, respectively ${ }^{23}$. The shift in obesity trends among school children is displayed in Fig. 1. The problem of obesity was more evident in students from private schools than in those from public schools or from rural areas, and tended to be more pronounced in urban communities than in rural communities.

Table 2 Trends in dietary intake of energy, protein, fat and carbohydrate in Thailand, 1960-1995

\begin{tabular}{lrrrr}
\hline & \multicolumn{4}{c}{ Year of survey } \\
\cline { 2 - 5 } & \multicolumn{1}{c}{1960} & \multicolumn{1}{c}{1975} & \multicolumn{1}{c}{1986} & 1995 \\
\hline Energy (kcal) & 1821 & 1749 & 1766 & 1751 \\
Protein (g) & 49.1 & 50.2 & 50.8 & 58.1 \\
As percentage of energy & 10.8 & 11.5 & 11.5 & 13.2 \\
Percentage of intake from animal sources & 31.0 & 39.0 & 45.1 & 51.1 \\
Fat (g) & 18.0 & 25.5 & 42.6 & 45.6 \\
As percentage of energy & 8.9 & 13.1 & 21.8 & 22.2 \\
Carbohydrate (g) & 359.0 & 310.6 & 293.7 & 276.9 \\
As percentage of energy & 78.9 & 71.0 & 66.7 & 64.3 \\
\hline
\end{tabular}

Source: Nutrition Division, Department of Health, Ministry of Public Health ${ }^{18,19}$. 


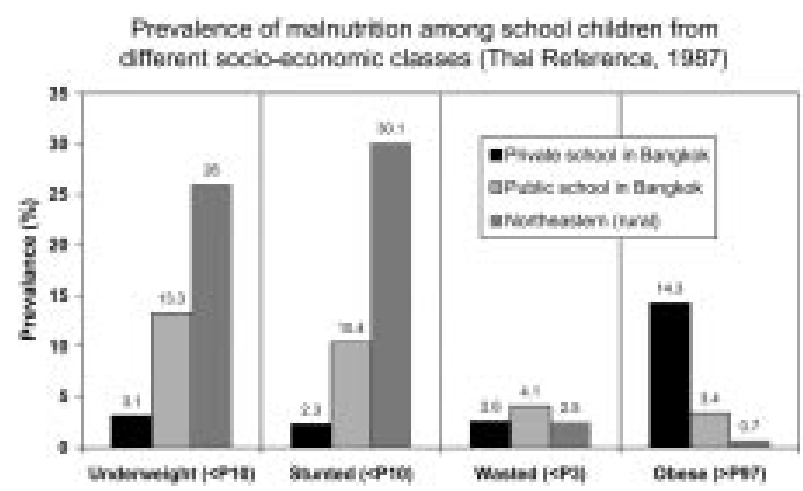

Prevalence of obesty in primary sctool children in a Bangkok public school (Thai Reference, 15e7)

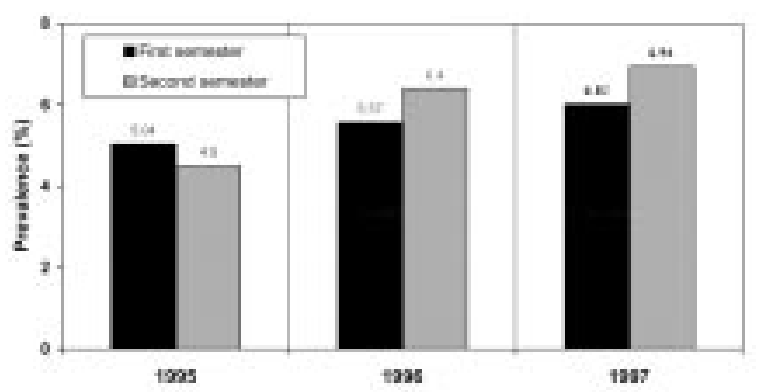

Prevalence of obesity in actrod chidren (1994-1995) (Thai Feference, 15e7)

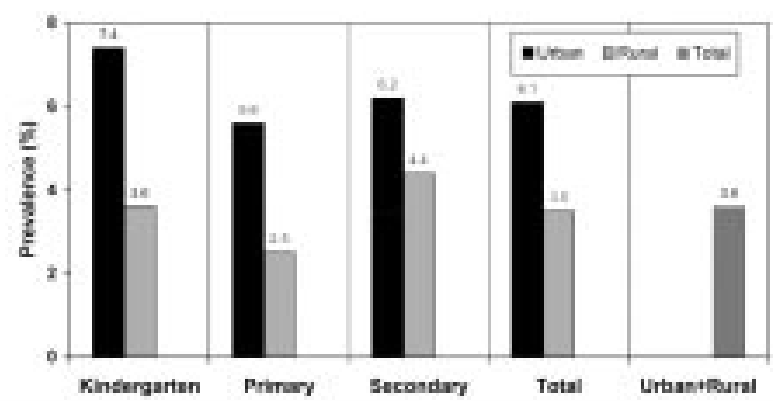

Fig. 1 Prevalence of under- and overnutrition among Thai school children. Source: Nutrition Division, Ministry of Public Health

\section{Adult population}

The obesity rate among adult Thais is increasing, especially among the affluent urban population. In 1985 , $25.5 \%$ of men and $21.4 \%$ of women were classified as overweight and obese in a study among 3495 officials (aged 35-54 years) of the Electricity Generating Authority of Thailand. Another study among 519 affluent urban Thais also demonstrated the prevalence of overweight and obesity, when $18.2 \%$ of the men and $27.0 \%$ of the women were found in this category ${ }^{21}$. Obesity is considered one of the major risk factors of diet-related chronic degenerative diseases among the Thai population. Nation-wide surveys in 1991 and 1996 indicated an increased prevalence of overweight and obesity in both adult men and women
(7.7\% vs. $13.2 \%$ in men and $15.7 \%$ vs. $25.0 \%$ in women) (Table 3). The prevalence of overweight and obesity was more pronounced in Bangkok and in the Central region of Thailand $^{24,25}$.

\section{Trends in disease patterns}

\section{Major causes of deatb}

The change in the Thai lifestyle, along with the development of the national economy, has significantly changed the disease pattern in Thailand. One example is a shift from predominantly communicable diseases to noncommunicable diseases such as cancer, cardiovascular disease, diabetes and obesity. The mortality rates of acute

Table 3 Prevalence of underweight (body mass index $(\mathrm{BMI})<18.5 \mathrm{~kg} \mathrm{~m}^{-2}$ ) and overweight $\left(\mathrm{BMI} \geq 25.0 \mathrm{~kg} \mathrm{~m}^{-2}\right.$ ) among the adult Thai population, classified by sex and geographical area (1991 and 1996)

\begin{tabular}{|c|c|c|c|c|c|c|c|c|}
\hline & \multicolumn{4}{|c|}{ NHES I (1991)* } & \multicolumn{4}{|c|}{ NHES II (1996)† } \\
\hline & \multicolumn{2}{|c|}{ Men } & \multicolumn{2}{|c|}{ Women } & \multicolumn{2}{|c|}{ Men } & \multicolumn{2}{|c|}{ Women } \\
\hline & $\begin{array}{c}\text { Underweight } \\
(\%)\end{array}$ & $\begin{array}{c}\text { Overweight } \\
(\%)\end{array}$ & $\begin{array}{c}\text { Underweight } \\
(\%)\end{array}$ & $\begin{array}{c}\text { Overweight } \\
(\%)\end{array}$ & $\begin{array}{c}\text { Underweight } \\
(\%)\end{array}$ & $\begin{array}{c}\text { Overweight } \\
(\%)\end{array}$ & $\begin{array}{c}\text { Underweight } \\
(\%)\end{array}$ & $\begin{array}{c}\text { Overweight } \\
(\%)\end{array}$ \\
\hline Bangkok & 43.8 & 14.2 & 40.9 & 16.9 & 25.1 & 21.9 & 16.1 & 35.5 \\
\hline Central & 57.2 & 8.1 & 35.0 & 19.8 & 30.2 & 16.2 & 23.3 & 29.8 \\
\hline North & 56.6 & 7.7 & 42.9 & 12.8 & 36.8 & 9.6 & 32.4 & 20.2 \\
\hline Northeast & 59.3 & 4.7 & 43.8 & 14.7 & 31.8 & 11.7 & 29.4 & 20.0 \\
\hline South & 60.7 & 7.4 & 44.8 & 13.1 & 34.8 & 13.2 & 24.9 & 25.7 \\
\hline Total & 56.9 & 7.7 & 41.0 & 15.7 & 32.4 & 13.2 & 26.1 & 25.0 \\
\hline
\end{tabular}

Sources: *, National Health Examination Survey (NHES) I, age group $>20$ years ${ }^{24}$; $\dagger$, NHES II, age group 13-59 years ${ }^{25}$. 
infectious disease including diarrhoea and pneumonia have decreased significantly since the early 1980s based on statistics from the Ministry of Public Health ${ }^{26-30}$. In contrast, diseases of the circulatory system have become the leading causes of death; the mortality rate from these diseases began to accelerate rapidly around 1995 and has become the number one cause of death in Thailand since the late 1980s. Cancer became another significant cause of death, and is ranked as the number three cause of death since the late 1980 s.

\section{Prevalence of important risk factors for cardiovascular disease in Thailand}

As mentioned earlier, diseases of the circulatory system have been the leading cause of death in Thailand since 1989 and ischaemic heart disease mortality has been increasing progressively each year ${ }^{31}$. The morbidity trend also indicated hypertension and ischaemic heart disease to account for the largest proportion of circulatory system diseases and the incidences of these two are increasing at an alarming rate. Based on the current mortality rate of cardiovascular disease among the Thai population, it is postulated that there would be 167 deaths from cardiovascular disease each day, or seven persons would die every hour, from cardiovascular disease (Sritara P, personal communication). Results from the First National Health Examination Survey (NHES) conducted in 1991 indicated that 2.2 million adult Thais suffered from hypertension (using the hypertension definition of average systolic blood pressure $\geq 160 \mathrm{mmHg}$ and/or diastolic $\geq 95 \mathrm{mmHg}$, and self-reported use of antihypertensive medication during the past week). If the latest criteria for hypertension were adopted (160/90 mmHg), the number of adult Thais with hypertension would increase to six million. Comparative results of the age-standardised (based on the world standard population) prevalence of cardiovascular risk factors derived from two national surveys in 1991 and 1996 (Suriyawongpaisal P, personal communication) demonstrated a significant increase in the prevalence of all major risk factors for cardiovascular disease among adult Thais, except for the prevalence of hypertension in women and smoking in both sexes. However, a study of affluent urban Thais (3495 officials of the Electricity Generating Authority of Thailand, aged 35-54 years) showed that, after 12 years of follow-up, the prevalence of all risk factors for cardiovascular disease increased significantly (Sritara P, personal communication); these are obesity, hypertension, diabetes, hypercholesterolaemia and smoking. The average cholesterol level of the urban Thais was $238 \mathrm{mg} \mathrm{dl}^{-1}$ - higher than the average value of Americans $\left(206 \mathrm{mg} \mathrm{dl}^{-1}\right)$. The problems of hypertension, hypercholesterolaemia and diabetes mellitus are not confined to the urban or affluent community; they are also considered a serious problem that needs immediate action in middle- to poor-income groups (e.g. in urban slums and other regions of Thailand) ${ }^{32}$.

\section{Food and nutrition policy in Thailand ${ }^{22,33}$}

Historically, Thailand's nutrition programme has been one of the components of the National Health Development Plan. The programme was implanted in the early 1960s and in conjunction with the National Economic and Social Development Plan (NESDP), when it was realised that nutrition and socio-economic development go hand in hand. However, an important drawback was that nutritional problems were treated only as deficiency diseases. Until the mid-to-late 1970s, the First National Food and Nutrition Plan (NFNP) was a separate entity in the Fourth NESDP (1977-1981). As a result, by the mid 1980s, Thailand dramatically reduced the prevalence of protein-energy malnutrition in pre-school children; only $3-5 \%$ of children under five suffered from moderate-tosevere forms of malnutrition. At the same time, the government realised that Thailand was faced with the phenomena of concurrent economic and health transitions. Therefore, the Fourth NFNP under the Seventh NESDP (1992-1996) continued to focus on achieving a 'better quality of life' rather than 'having good bealth'. It was set into action via the Basic Minimum Needs (BMN) approach. This approach contained key indicators of the nutritional development and improvement of school children and children $<5$ years of age. It also included newly emerging issues associated with Thailand's socioeconomic transformation, such as food sanitation and safety, as well as a focus on the role of nutrition in chronic degenerative diseases. One of the major achievements during this national plan was the establishment of the first set of Dietary Guidelines for Thailand in 1989, which addressed both under- and over-nutrition as well as breast-feeding issues. These 1996 drafted guidelines, The Thai Dietary Guidelines for Better Health, have been adapted to correspond with the emerging problems of chronic diet-related degenerative diseases ${ }^{34}$. They were intended to be used as a tool to promote appropriate diets and improve health for everyone under the Fourth NFNP through nutrition education. The current, Eighth NESDP (1997-2001) or the Fifth NFNP continues the food and nutrition movement by aiming at achieving the long-term vision of an ideal Thai society. The goal of the current NFNP remains focused on improving quality of life by ensuring household food and nutrition security. The main actions include controlling and eliminating the problem of malnutrition in vulnerable groups; improving household food security; promoting production, processing, distribution and consumption of nutritious food; and protecting the rights of consumers. Several nation-wide implementation programmes such as promotion of a physically active lifestyle and healthy eating in school settings, in the 
workplace and in high-risk groups such as the elderly, were initiated during the last half of the plan.

\section{Conclusion}

This emerging nutrition crisis in the region is considered a new challenge for health and nutrition professionals to address the appropriate preventive measures for both under- and overnutrition. The successful experience in our country of combating the undernutrition problem, protein-energy malnutrition in children $<5$ years old in particular, through a community-based participatory programme clearly indicated that if appropriate action is undertaken, prevention and control of diet-related chronic disease in Thailand could also be achieved. However, greater attention needs to be placed on understanding daily life dietary practices, work-related behaviours, physical activities and family food consumption practices; this is in addition to how Thais perceive such behaviours in relation to their own health and quality of life. Subsequently, these rapid changes in food intake and lifestyle patterns should be carefully monitored and must be reversed through appropriate behaviour modification and the promotion of appropriate eating practices and physical activities.

\section{References}

1 Powles J. Changing lifestyles and health. Asia Pacific J. Clin Nutr. 1992; 1: 113-26.

2 Vorsler HH, Borne LT, Venter CS, Oosthuizen W. Contribution of nutrition to the health transition in developing countries: a framework for research and intervention. Nutr. Rev. 1999; 57: 341-9.

3 Popkin BM. The nutrition transition in low-income countries: an emerging crisis. Nutr. Rev. 1994; 52: 285-98.

4 Popkin BM. Nutritional pattern and transition. Popul. Dev Rev. 1993; 19: 138-57.

5 Kim S, Moon S, Popkin BM. The nutrition transition in South Korea. Am. J. Clin. Nutr. 2000; 71: 44-53.

6 Popkin BM, Keyou G, Fenying Z, Guo X, Haijiang M, Zohoori N. The nutrition transition in China: a crosssectional analysis. Eur. J. Clin. Nutr. 1993; 47: 333-46.

7 Chunming C. Eating patterns - a prognosis for China. Asia Pacific J. Clin. Nutr. 1995; 4(Suppl. 1): 24-8.

8 Drewnowski A, Popkin BM. The nutrition transition: new trends in the global diet. Nutr. Rev. 1997; 55: 31-43.

9 Popkin BM. The nutrition transition and obesity in the developing world. J. Nutr. 2001; 131: 871s-3s.

10 Kachondham Y, Winichagoon P, Tontisirin K, eds. Nutrition and Health in Thailand: Trends and Actions. UN ACC/SCN Country Case Study supported by UNICEF Institute of Nutrition, Mahidol University at Salaya, Bangkok: P I Printing, 1992.

11 Wibulpholprasert S, ed. Public Health in Thailand 19971998. Bangkok: Ministry of Public Health, 1999.

12 National Statistical Office. Report of the 1990 Household Socio-economic Survey Whole Kingdom. Bangkok, Religious Printing.

13 National Statistical Office. Report of the 1992 Household Socio-economic Survey Whole Kingdom. Bangkok: Aksorn Thai Printing.
14 National Statistical Office. Report of the 1994 Household Socio-economic Survey Whole Kingdom. Bangkok: P A Living Co.

15 National Statistical Office. Report of the 1996 Household Socio-economic Survey Whole Kingdom. Bangkok: P A Living Co.

16 National Statistical Office. Report of the 1998 Household Socio-economic Survey Whole Kingdom. Bangkok: P A Living Co.

17 The Kingdom of Thailand. Nutrition Survey OctoberDecember 1960. A report by the Interdepartmental Committee on Nutrition for National Defence. Bangkok: Interdepartmental Committee on Nutrition for National Defence, 1992.

18 Nutrition Division, Department of Health, Ministry of Public Health. The Third National Nutrition Survey of Thailand 1986. Bangkok: War Veterans Organization Printing, 1995.

19 Nutrition Division, Department of Health, Ministry of Public Health. The Fourth National Nutrition Survey of Thailand 1995. Bangkok: War Veterans Organization Printing, 1997.

20 Food and Agriculture Organization (FAO) of the United Nations. Selected Indicators of Food and Agriculture Development in Asia-Pacific Region, 1989-99. RAP Publication 2000/15 Rome: FAO, 1999.

21 Tanphaichitr V, Pakpeankitvatana R, Leelahagul P, Achariyanont P, Viruenchavee N. Dyslipidemia in urban Thais. Biomed. Environ. Sci. 1996; 9: 199-203.

22 Tontisirin K, Kachondam Y, Winichagoon P. Trends in the development of Thailand's nutrition and health plans and programs. Asia Pacific J. Clin. Nutr. 1992; 1: 195-206.

23 Nutrition Division, Department of Health, Ministry of Public Health. Report of the Situation of Overnutrition in Kindergarten and Primary School Children in Thailand [in Thai]. Nonthaburi: Ministry of Public Health, 2000.

24 Chuprapawan C. Report of the First National Health Examination Survey in Thailand [in Thai]. Bangkok: Ministry of Public Health, 1991.

25 Chuprapawan C. Report of the Second National Health Examination Survey in Thailand [in Thai]. Nonthaburi: Ministry of Public Health, 2000.

26 Ministry of Public Health. Public Health Statistics 19771981. Nonthaburi: Ministry of Public Health, 1983.

27 Ministry of Public Health. Public Health Statistics 1987. Nonthaburi: Ministry of Public Health, 1988.

28 Ministry of Public Health. Public Health Statistics 1990. Nonthaburi: Ministry of Public Health, 1991.

29 Ministry of Public Health. Public Health Statistics 1995. Nonthaburi: Ministry of Public Health, 1996.

30 Ministry of Public Health. Public Health Statistics 1998. Nonthaburi: Ministry of Public Health, 2000.

31 Tatsanavivat $\mathrm{P}$, Klungboonkrong V, Chirawatkul A, Bphuripanyo K, Manmontri A, Chitanondh H, Yipintsoi T. Prevalence of coronary heart disease and major cardiovascular risk factors in Thailand. Int. J. Epidemiol. 1998; 27: 405-409.

32 Kamolsiripichaiporn P, Yipintsoi T. Prevalence of Some Cardiovascular Risk Factors in Thailand from Published Articles. Bangkok: Thailand Heart Association/Sawicharn Printing, 2000 .

33 Kosulwat V. Food and nutrition policy in Thailand. In: Proceedings of the 2nd Asian Congress of Dietetics: Networks $\&$ New Ventures for Asian Dietetics, Seoul, Korea. Seoul: The Korean Dietetic Association, 1998; 80-6.

34 Tontisirin K, Kosulwat V. Food-based dietary guidelines in Asian countries. In: Shetty P, Gopalan C, eds. Diet, Nutrition and Chronic Disease: An Asian Perspective. London: SmithGordon/Nishimura, 1998; 105-11. 